\title{
Assessment of Nutritional Status of Patients with Chronic Hepatitis C and HCV-Related Cirrhosis in the Compensated Stage
}

\author{
Hoda M. Amin ${ }^{1}$, Rasha M. Abdel Samie ${ }^{1, ~ *, ~ F a r d o u s ~ S . ~ H a m e d ~}{ }^{2}$, Ebtehal M. Abo Zaid ${ }^{1}$, \\ EI Sayed M. Hammad 2 \\ ${ }^{1}$ Internal Medicine Department, Faculty of Medicine, Cairo University, Cairo, Egypt \\ ${ }^{2}$ Clinical Nutrition Department, National Nutrition Institute, Cairo, Egypt
}

\section{Email address}

hodamamin@yahoo.com (H. M. Amin),drrasha76@gmail.com (R. M. Abdel Samie), fardous_soliman@hotmail.com (F. S. Hamed), yehia820@yahoo.com (E. M. Abo Zaid),Dr_sayedhammad@yahoo.com (E. M. Hammad)

\section{To cite this article:}

Hoda M. Amin, Rasha M. Abdel Samie, Fardous S. Hamed, Ebtehal M. Abo Zaid, El Sayed M. Hammad. Assessment of Nutritional Status of Patients with Chronic Hepatitis C and HCV-Related Cirrhosis in the Compensated Stage. American Journal of Internal Medicine.

Vol. 4, No. 2, 2016, pp. 24-35. doi: 10.11648/j.ajim.20160402.11

\begin{abstract}
Background and Aim: Malnutrition is prevalent among patients with chronic liver disease. We aimed to assess the nutritional status of $\mathrm{HCV}$-related compensated cirrhosis and chronic $\mathrm{HCV}$-infected patients compared to healthy control subjects and to compare the different methods used for nutritional assessment namely the anthropometric measures and the Subjective Global Assessment (SGA). Patients and Methods: A total of 120 subjects were recruited. 40 patients with hepatitis C- related compensated liver cirrhosis in Group I, 40 patients with chronic hepatitis C in Group II and 40 age - and sexmatched healthy Egyptian volunteers in Group III. Thorough history taking, physical examination and detailed nutritional assessment were performed including a 24- hour dietary recall. Evaluation of nutritional status was done using different anthropometric measures and the Subjective Global Assessment (SGA). Results: Chronic HCV patients were found to have lower mean daily caloric intake $(1858.70 \pm 630.2 \mathrm{Kcal} /$ day $)$ as compared to patients with compensated cirrhosis $(1923.75 \pm 595.8 \mathrm{Kcal} / \mathrm{day})$. The diagnosis of severely malnourished was detected with an increased frequency in the cirrhotic patients by the triceps skin fold thickness (TST) method (52.5\%) as compared to mid-arm muscle circumference (MAMC) $(30 \%)$ and the sub-scapular skin fold thickness $(15 \%)$. In the chronic HCV patients, an increased frequency of diagnosis of malnutrition was detected by the MAMC\% (57.5\%) as compared to the other anthropometric indices. Based on the SGA rating, moderate degree of malnutrition was detected in $37.5 \%$ of cirrhotic patients and only $27.5 \%$ of chronic HCV patients, however, severe degree of malnutrition was not diagnosed in any of the subjects. The majority of the patients with compensated HCV related cirrhosis and chronic HCV group as well as controls were found to be overweight $67.5 \%, 62.5 \%$ and $62.5 \%$ respectively. There was a highly significant positive correlation between the BMI and the TST, MAC, MAMC, and sub-scapular skin fold thickness in the three studied groups. Conclusion: Overweight was prevalent among patients with chronic $\mathrm{HCV}$ and compensated cirrhosis. SGA underestimated the degree and prevalence of malnutrition as compared to TST, MAMC and sub-scapular skin fold thickness in the liver cirrhosis, chronic hepatitis $\mathrm{C}$ and healthy control groups.
\end{abstract}

Keywords: Chronic HCV-compensated Cirrhosis-SGA-TST- MAMC

\section{Introduction}

Malnutrition is an increasingly recognized complication of chronic liver disease and has been considered an important prognostic factor greatly affecting the short and long term outcomes of these patients and determining their quality of life and survival. Many studies of nutritional status have demonstrated that malnutrition occurs in all forms of cirrhosis of varying aetiologies and varying degrees of hepatic insufficiency $[1,2]$. The prevalence varied according to the methods employed for nutritional assessment and the severity of liver disease. It was reported to be $65-90 \%$ in patients with advanced liver disease [3] and even as high as $25 \%$ in cirrhotic patients with Child-Pugh class A [4], with the prevalence reaching almost $100 \%$ in patients who are candidate for liver 
transplantation [5].

Hepatitis $\mathrm{C}$ virus is one of the chief causes of chronic liver disease [6]. Hepatitis $\mathrm{C}$ related liver disease encompasses a wide spectrum ranging from chronic hepatitis $\mathrm{C}$ to compensated cirrhosis and eventually to decompensated cirrhosis and hepatocellular carcinoma. Protein energy malnutrition (PEM) is a frequently reported finding in patients with liver cirrhosis (LC), and its severity increases with worsening liver functions [7] mainly in situations of metabolic stress associated with the presence of infection and/or hospitalization [8]. PEM in cirrhotic patients also has important implications in liver transplantation and it has been demonstrated that patients with a worse nutritional status before the transplant have increased postoperative complications and higher mortality rates $[9,10]$.

Recently, a great diversity has been observed as regard the nutritional status of patients with liver cirrhosis with some showing protein energy malnutrition and others excessive nutrition and obesity [11]. Many studies have investigated the prevalence of malnutrition using different methods of nutritional assessment and have reported inadequate energy and protein intake in cirrhotic patients awaiting liver transplantation [12-17] however there are few studies regarding nutritional intake and assessment in patients with chronic hepatitis $\mathrm{C}$ virus without complications, such as cirrhosis $[16,18]$, or the compensated cirrhotic HCV patients and how they compare to the normal population [18]. No gold standard have yet been established for the diagnosis of malnutrition in patients with liver disease.

The progressive increase in obesity and the metabolic syndrome is a significant problem in many advanced countries. An increased prevalence of overweight and obesity in patients with liver cirrhosis has been reported in a large scale Japanese study [19]. Accordingly, PEM may not be observed as a common complication of liver cirrhosis, particularly in the compensated stage. This may be because branched-chain amino acids (BCAA)-enriched nutrients have been developed and actively applied in clinical settings and dietary habits have recently changed to overeating [20-22]. Therefore for nutritional management of liver cirrhosis patients it is important to precisely assess the patient's nutritional intake and to establish effective nutritional education programs [11]. The aim of our study was to assess the nutritional status of HCV-related cirrhotic patients in the compensated stage, chronic HCV patients and to evaluate how they compare with normal healthy control subjects. We also aimed at evaluating their dietary intake and comparing the different methods used for nutritional assessment namely the anthropometric measures and the Subjective Global Assessment (SGA).

\section{Patients and Methods}

A total of 120 subjects were recruited in the present study and included 40 patients with hepatitis C- related liver cirrhosis (Group I), 40 patients with chronic hepatitis $\mathrm{C}$ (Group II), and 40 age- and sex- matched healthy Egyptian volunteers (Group III).They were enrolled in the study between February 2015 and July 2015. All subjects were recruited from outpatient clinic and inpatient section of Internal Medicine Department, Kasr El Ainy Hospital, Cairo University. Liver cirrhosis was diagnosed on the basis of clinical features, documented laboratory tests and/or abdominal ultrasound. Child-Turcotte Pugh (CTP) score was used to establish the severity of liver cirrhosis.

All hepatitis C- related liver cirrhosis patients enrolled were in the compensated stage; had no history of decompensation, and an ultrasound showing features of cirrhosis with or without portal hypertension, but no ascites. The patients with chronic hepatitis $\mathrm{C}$ infection were those who had evidence of HCV viraemia, raised serum transaminases, normal liver synthetic function, and an ultrasound of the liver showing absence of portal hypertension, such as a dilated portal vein, or splenomegaly. The study protocol was approved by the Ethics Committee of the Internal Medicine Department and an informed consent was obtained from all participants prior to enrolment in accordance with the ethical guidelines of the Declaration of Helsinki [23].

Inclusion criteria were patients aged above 18 years and Child A post -hepatitis C. Exclusion criteria included cirrhotic patients with child $\mathrm{B}$ or $\mathrm{C}$, ascites and or hypoalbuminemia (less than $3.5 \mathrm{~g} / \mathrm{dl}$ ), other causes of cirrhosis other than HCV (alcoholic or autoimmune hepatitis), pregnancy and breast feeding, acquired immunodeficiency syndrome, patients with malignancy (eg. hepatocellular carcinoma), other chronic diseases (as chronic renal failure, hypertension, heart failure, etc) and patients with systemic inflammatory response syndrome or septic shock.

All subjects were subjected to thorough history taking and physical examination. A detailed nutritional assessment was performed by a single dietitian specialized in liver disease. The evaluation of nutritional status was done by different methods. All cases and controls were subjected to detailed dietary history including appetite, caloric intake and change in body weight.

\subsection{Anthropometry}

The nutritional status was also evaluated using anthropometric measures. For anthropometric assessment the body weight, height, triceps skin fold thickness (TST), mid arm circumference and mid-arm muscle circumference (MAMC), were measured. The triceps skin fold thickness was calculated as the mean of three measurements using Harpenden skin fold caliper midway between the acromion and the tip of olecranon. The arm circumference was measured at the right arm at a midpoint equidistant from acromion and olecranon with patient in upright position and arm flexed at 90 . The MAMC was calculated; MAMC (mm) $=$ MAC $-\{\pi \times$ TST $(\mathrm{mm})\}$. The body mass index (BMI) was also calculated $\left(B M I=\right.$ weight $/$ height ${ }^{2}\left(\mathrm{~kg} / \mathrm{m}^{2}\right)$. Triceps Skin fold Thickness (TST) was used to estimate body fat, measured on the right arm halfway between the olecranon process of the elbow and the acromial process of the scapula, measured by a skin folder. Measurement of the subscapular skinfold thickness was done as follows: the assessor stood behind the 
subject and located the subscapular skin fold site which is located $1 \mathrm{~cm}$ below the inferior angle of the scapula.The assessor then grasped and lifted the subcutanous tissue and skin at a dowward angle of approximately 45 degrees towards the lateral aspect of the body, then placed the pincers of the skin fold caliper at a depth of $1 \mathrm{~cm}$ and held this position for 3 to 4 seconds. This provided the actual skin fold thickness in $\mathrm{mm}$. The percentiles for anthropometric measures were adapted from Anthropometric Reference Data for Children and Adults: United States, 1988 - 1994, based on data from the Third National Health and Nutrition Examination Survey (NHANES III) [24].

The nutritional status was then classified into three classes; well nourished, mild to moderate malnourished and severely malnourished according to Blackburn and Harvey (25).

\subsection{4- hour Dietary Recall}

Was used to assess dietary intake. Energy and protein intake were compared to Food Composition tables for Egypt: National Nutrition Institute of Cairo, A.R.E, Second edition, May 2006 [26] (Classification of Energy and protein intake into average, overconsumption or insufficient intake was done according to the Recommended Dietary Allowance (RDA) in chronic liver disease, Food and Nutrition Board, Institute of Medicine: Dietary Reference Intake for energy, carbohydrate, fibre, fat, fatty acids, cholesterol, protein and amino acid (Macronutrients), Washington, DC: The National Academies Press, 2005) [27].

\subsection{Subjective Global Assessment}

The Subjective Global Assessment (SGA) according to the proposition by Detsky et al. [28] was used. It is a simple evaluative tool which can be administered at the bedside and includes a focused history and physical examination that allows a physician to assess the patient's nutritional status [29] and is a strong predictor of malnutrition in cirrhotic patients [30].

Standardized batteries of questions and physical examination findings have been evaluated for nutritional assessment. The historical components of the SGA include weight loss, change in dietary intake, presence of gastrointestinal symptoms, functional capacity and the metabolic demand associated with the disease state. Physical examination components include the presence of edema, ascites, muscle wasting, and subcutaneous fat loss. The presence of muscle wasting and subcutaneous fat loss is suggestive of severe malnutrition. Components are combined to obtain an SGA rating ranging from well-nourished to severely malnourished [31]. Patients were classified as wellnourished SGA (Grade A), moderately or suspected of being malnourished (Grade B) and severely malnourished SGA (Grade C) [32].

\subsection{Laboratory Investigations}

Laboratory investigations done included complete blood count $(\mathrm{CBC})$, sodium, potassium, serum urea, creatinine, serum albumin, total and direct bilirubin, ALT, AST, coagulation profile including PT, PC and INR and lipid profile (including triglycerides, total cholesterol, LDL-C and HDL-C).

\subsection{Abdominal Ultrasound}

Was performed using a Toshiba Apilo XV scanner equipped with a broad band 5.3 megaHertz curved array probe and by the same operator to avoid inter-observer variability.

\subsection{Statistical Analysis}

The data was coded and entered using the statistical package SPSS version 13 analysis. The data was summarized using descriptive statistics: mean, standard deviation, median, minimal and maximum values for quantitative variables and number and percentage for qualitative values. Statistical differences between the groups were tested using the Chi-Square test for qualitative variables, independent sample $\mathrm{t}$ - test for quantitative normally distributed variables. Analysis of variance with multiple comparison ANOVA test was used for normally distributed quantitative variables, while non-parametrical Mann-Whitney test was used for quantitative variables which were not normally distributed. Non-parametrical correlations were carried out using Spearman test, for linear relations between BMI and TST, MAMC, MAC, sub-scapular skin fold thickness and SGA in the three groups. $\mathrm{P}$ values $<0.05$ were considered.

\section{Results}

A total of 120 subjects were enrolled, equally divided amongst the three groups: compensated HCV-liver cirrhosis, chronic HCV and healthy control groups. The liver cirrhosis group included 21 males and 19 females and their age ranged from 20-65 years. The chronic HCV group included 24 males and 16 females and their age ranged from $24-70$ years. The gender was also comparable in the healthy control group and their age ranged from 20-60 years. The clinical, biochemical and nutritional parameters of the different studied groups are summarized in Tables 1 and 2 . There were highly significant differences between the liver cirrhosis, chronic HCV and healthy control groups as regard the serum AST and ALT levels $(p=0.000)$, total bilirubin $(p=0.000)$, albumin $(p=0.000)$, and prothrombin concentration. Regarding the mean values of the anthropometric measurements, there were significant differences between the studied groups as regard the TST $(p=0.009)$ and the sub-scapular skinfold thickness $(p=0.006)$.

There were highly significant statistical differences between the different studied groups as regard the different components of the SGA namely weight loss $(p=0.008)$, dietary intake $(\mathrm{p}=0.013)$, functional capacity $(\mathrm{p}=0.008)$, and GIT symptoms $(\mathrm{p}=0.008)$. On the SGA rating, however, no significant differences were observed between the studied groups. The majority of patients in the liver cirrhosis (25/40(62.5\%)), chronic HCV (29/40(72.5\%)) and healthy control $(37 / 40(92.5 \%))$ groups were found to be well 
nourished (scored an 'A' on the SGA rating); the rest were found to be mild -moderately malnourished $(37.5 \%, 27.5 \%$, and $7.5 \%$ respectively) and none of the subjects of the three studied groups were found to be severely malnourished on the SGA rating (Fig. 1).

Table 1. Comparison of the clinical characteristics and laboratory variables between the different studied groups.

\begin{tabular}{|c|c|c|c|c|}
\hline Variable & Group I (Liver cirrhosis) & Group II (Chronic HCV) & Group III (Control) & p value \\
\hline Age (years) & $48.15 \pm 12.4$ & $41.02 \pm 11.5$ & $32.65 \pm 8.7$ & 0.6 \\
\hline BMI $\left(\mathrm{kg} / \mathrm{m}^{2}\right)$ & $27.39 \pm 4.7$ & $27.60 \pm 2.1$ & $27.52 \pm 2.9$ & 0.983 \\
\hline AST (IU/L) & $64.93 \pm 34.7$ & $51.63 \pm 35.1$ & $25.33 \pm 15.4$ & 0.000 \\
\hline ALT (IU/L) & $56.58 \pm 34.5$ & $52.65 \pm 34.7$ & $25.88 \pm 17.6$ & 0.000 \\
\hline Total Bilirubin (mg/dL) & $1.06 \pm 0.2$ & $1.02 \pm 0.3$ & $0.84 \pm 0.2$ & 0.000 \\
\hline Direct Bilirubin (mg/dL) & $0.38 \pm 0.2$ & $0.32 \pm 0.1$ & $0.29 \pm 0.2$ & 0.063 \\
\hline Albumin (g/dL) & $3.70 \pm 0.8$ & $3.93 \pm 0.2$ & $3.98 \pm 0.7$ & 0.000 \\
\hline Creatinine $(\mathrm{mg} / \mathrm{dL})$ & $0.89 \pm 0.2$ & $0.82 \pm 0.3$ & $0.85 \pm 0.2$ & 0.325 \\
\hline Platelets & $232.68 \pm 85.2$ & $241.08 \pm 90.7$ & $314.70 \pm 83.8$ & 0.000 \\
\hline $\mathrm{Hb}(\mathrm{g} / \mathrm{dL})$ & $12.44 \pm 2.0$ & $12.13 \pm 1.7$ & $12.55 \pm 1.5$ & 0.521 \\
\hline $\operatorname{TLC}\left(10^{3} / \mu \mathrm{L}\right)$ & $7.10 \pm 2.1$ & $5.22 \pm 1.7$ & $7.91 \pm 1.7$ & 0.160 \\
\hline $\mathrm{PC}(\%)$ & $91 \pm 0.1$ & $93.05 \pm 4.6$ & $99.30 \pm 1.99$ & 0.000 \\
\hline INR & $1.13 \pm 0.1$ & $1.07 \pm 0.1$ & $1.01 \pm 0.04$ & 0.000 \\
\hline TG (mg/dL) & $152.51 \pm 44.1$ & $138.23 \pm 48.4$ & $160.88 \pm 48.3$ & 0.052 \\
\hline Total Cholesterol(mg/dL) & $158.78 \pm 44.1$ & $171.43 \pm 52.1$ & $174.80 \pm 60.9$ & 0.448 \\
\hline
\end{tabular}

All values are expressed as mean $\pm S D$. BMI=Body mass index; TLC=Total leucocytic count; PC= prothrombin concentration; TG=triglycerides. $P$ value is considered significant when $<0.05$, highly significant

Table 2. Comparison of the different anthropometric measures and daily protein and caloric intake between the studied groups.

\begin{tabular}{|c|c|c|c|c|}
\hline Parameter & Group I (Liver cirrhosis) & Group II (Chronic HCV) & Group III (Control) & p value \\
\hline TST (mm) & $10.93 \pm 7.9$ & $14.58 \pm 9.6$ & $16.15 \pm 10.9$ & 0.009 \\
\hline MAC (mm) & $268.10 \pm 49.0$ & $270.95 \pm 53.2$ & $286.00 \pm 41.8$ & 0.961 \\
\hline MAMC (mm) & $232.1 \pm 33.1$ & $232.1 \pm 26.9$ & $234.0 \pm 33.7$ & 0.953 \\
\hline Subscapular SFT (mm) & $15.08 \pm 7.7$ & $20.23 \pm 11.0$ & $21.43 \pm 10.4$ & 0.006 \\
\hline Daily Protein intake (gm) & $76.53 \pm 23.6$ & $76.13 \pm 32.9$ & $82.43 \pm 27.1$ & 0.344 \\
\hline Daily Caloric intake (kCal) & $1923.75 \pm 595.8$ & $1858.70 \pm 630.2$ & $2056.20 \pm 613.2$ & 0.424 \\
\hline
\end{tabular}

All values are expressed as mean \pm SD. BMI: body mass index, TST: Triceps skin fold thickness MAC: mid arm circumference, MAMC: Mid-arm muscle circumference. P value is considered significant when $<0.05$, highly significant when $p$ value $<0.001$.

Table 3. Comparison between the daily caloric and protein intake in HCV-related cirrhosis group.

\begin{tabular}{|c|c|c|c|c|c|c|c|c|c|}
\hline & \multicolumn{6}{|c|}{ Caloric intake } & \multirow{2}{*}{\multicolumn{2}{|c|}{ Total }} & \multirow{3}{*}{ p value } \\
\hline & \multicolumn{2}{|c|}{ Insufficient } & \multicolumn{2}{|c|}{ Average } & \multicolumn{2}{|c|}{ Overconsumption } & & & \\
\hline & No & $\%$ & No & $\%$ & No & $\%$ & No & $\%$ & \\
\hline \multicolumn{10}{|l|}{ Protein Intake } \\
\hline Average & 2 & $5 \%$ & 3 & $7.5 \%$ & 8 & $20 \%$ & 13 & $32.5 \%$ & \multirow{3}{*}{0.011} \\
\hline Overconsumption & 4 & $10 \%$ & 18 & $45 \%$ & 5 & $12.5 \%$ & 27 & $67.5 \%$ & \\
\hline Total & 6 & $15 \%$ & 21 & $52.5 \%$ & 13 & 32.5 & 40 & $100 \%$ & \\
\hline
\end{tabular}

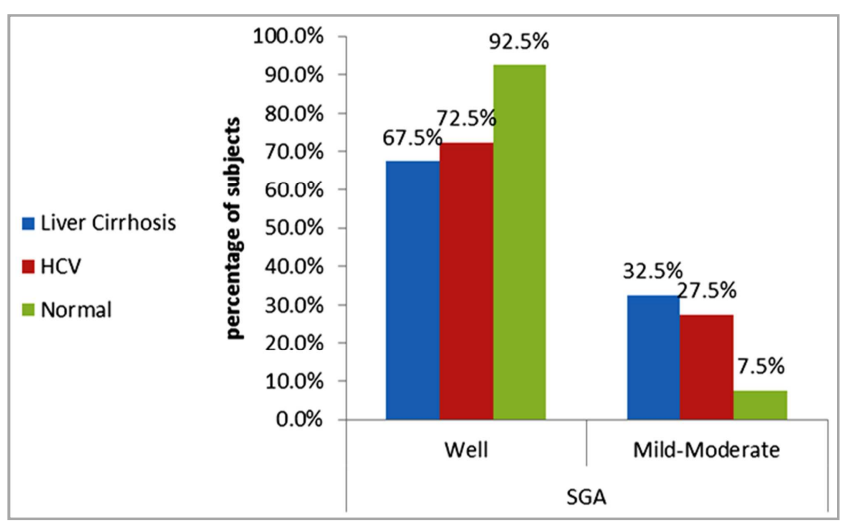

Fig. 1. Comparison of the nutritional status among the groups based on SGA.

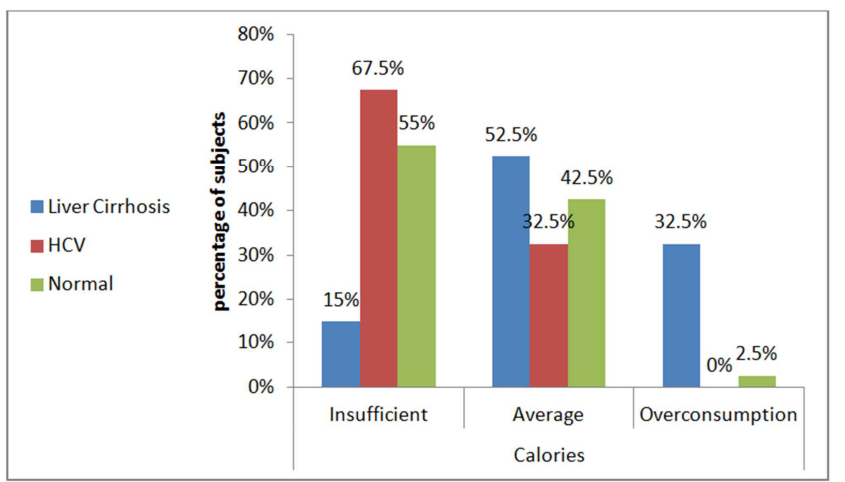

Fig. 2. Comparison of daily intake levels of calories among the cirrhotic patients, chronic hepatitis $C$ patients and controls. 
There was a significant association between the caloric and protein intake in the HCV-related cirrhosis group (p value $=0.0011$ ) (Table 3$)$.

The majority of the cirrhotic patients showed an average caloric intake (18/40(45\%)) and/or an excessive protein intake and only a minority $(2 / 40(5 \%))$ showed an insufficient caloric intake and/or an average protein intake. Caloric overconsumption was observed in $32.5 \%(13 / 40)$ of the cirrhotic patients (Fig. 2) with most of them having an average protein intake and the rest having an excessive protein intake.

Table 4. Comparison between the daily caloric and protein intake in chronic HCV group.

\begin{tabular}{|c|c|c|c|c|c|c|c|}
\hline & \multicolumn{6}{|c|}{ Caloric intake } & \multirow{3}{*}{ p value } \\
\hline & \multicolumn{2}{|c|}{ Insufficient } & \multicolumn{2}{|c|}{ Average } & \multicolumn{2}{|c|}{ Total } & \\
\hline & No & $\%$ & No & $\%$ & No & $\%$ & \\
\hline $\begin{array}{l}\text { Protein Intake } \\
\text { Insufficient }\end{array}$ & 3 & $7.5 \%$ & 3 & $7.5 \%$ & 6 & $15 \%$ & \\
\hline Average & 9 & $22.5 \%$ & 10 & $25 \%$ & 19 & $47.5 \%$ & 0.016 \\
\hline Overconsumption & 15 & $37.5 \%$ & 0 & $0 \%$ & 15 & $37.5 \%$ & \\
\hline Total & 27 & $67.5 \%$ & 13 & $32.5 \%$ & 40 & $100 \%$ & \\
\hline
\end{tabular}

$P$ value is considered significant when $<0.05$, highly significant when $p$ value $<0.001$.

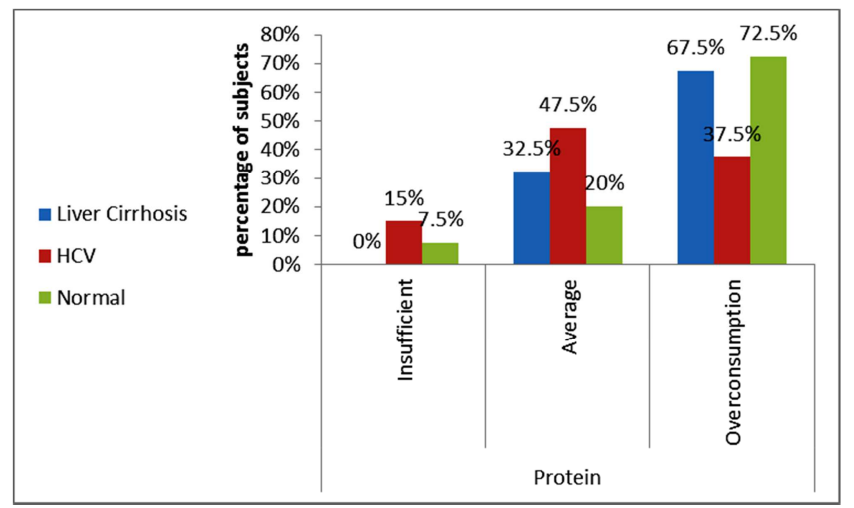

Fig. 3. Comparison of daily intake levels of protein among the cirrhotic patients, chronic hepatitis $C$ patients and controls.

A significant association between the mean daily caloric and protein intake was also observed in chronic hepatitis $\mathrm{C}$ group (Table 4 ) with a $\mathrm{p}$ value $=0.016$. The majority of the chronic HCV patients showed an insufficient caloric intake (67.5\%) and 32.5\% showed an average caloric intake (Fig. 2). Most of the chronic HCV patients with an insufficient caloric intake had an either excessive (15/27-55.6\%) or an average protein intake (9/27-33.3\%) (Fig. 3). Most of the chronic HCV patients who had an average caloric intake also had an average protein intake. An insufficient protein intake was observed in only $15 \%$ (6/40) of the chronic HCV patients (Fig. 3) and they were found to have an equal frequency of concomitant insufficient or an average caloric intake. An excessive caloric intake was not observed in the chronic HCV group (Fig. 2).

We did not observe any significant differences between the compensated liver cirrhosis, chronic HCV and healthy control groups as regard the daily intake of calories $(p=0.576)$ or proteins $(p=0.772)$ (Table 5). However, there was a higher prevalence of an insufficient caloric and protein intake in the chronic HCV group as compared to liver cirrhosis and healthy control groups. Patients with compensated cirrhosis had higher mean daily intake levels of calories and proteins than did patients with chronic $\mathrm{HCV}(1923.75 \pm 595.8 \mathrm{kCal} /$ day vs $1858.70 \pm 630.2 \mathrm{kCal} /$ day respectively and $76.53 \pm 23.6 \mathrm{~g} /$ day vs $76.13 \pm 32.9 \mathrm{~g}$ /day respectively). Moreover, regarding the protein intake a higher frequency of an excessive protein intake was also observed in patients with liver cirrhosis as compared to patients with chronic HCV.

Table 5. Comparison of daily intake levels of energy and protein among cirrhotic patients, chronic hepatitis C patients and controls.

\begin{tabular}{|c|c|c|c|c|c|c|c|}
\hline & \multicolumn{2}{|c|}{ Liver cirrhosis } & \multicolumn{2}{|c|}{ Chronic HCV } & \multicolumn{2}{|c|}{ Healthy controls } & \multirow{2}{*}{ p value } \\
\hline & $\mathrm{N}=\mathbf{4 0}$ & $\%$ & $\mathrm{~N}=\mathbf{4 0}$ & $\%$ & $\mathrm{No}=40$ & $\%$ & \\
\hline \multicolumn{8}{|l|}{ Calories } \\
\hline Insufficient & 6 & $15 \%$ & 27 & $67.5 \%$ & 22 & $55 \%$ & \multirow{3}{*}{0.576} \\
\hline Average & 21 & $52.5 \%$ & 13 & $32.5 \%$ & 17 & $42.5 \%$ & \\
\hline Overconsumption & 13 & $32.5 \%$ & 0 & $0 \%$ & 1 & $2.5 \%$ & \\
\hline \multicolumn{8}{|l|}{ Protein } \\
\hline Insufficient & 0 & $0 \%$ & 6 & $15 \%$ & 3 & $7.5 \%$ & \multirow{3}{*}{0.772} \\
\hline Average & 13 & $32.5 \%$ & 19 & $47.5 \%$ & 8 & $20 \%$ & \\
\hline Overconsumption & 27 & $67.5 \%$ & 15 & $37.5 \%$ & 29 & $72.5 \%$ & \\
\hline
\end{tabular}

$P$ value is considered significant when $<0.05$, highly significant when $p$ value $<0.001$.

Comparison of the nutritional status among the groups based on the different anthropometric measures and SGA (Table 6) showed only a significant difference between the liver cirrhosis, chronic HCV and control groups as regard nutritional status assessment by the TST $(p=0.027)$, however no significant differences were observed as regard the MAMC\% or sub-scapular skin fold thickness. When assessing the reproducibility of the different parameters of nutritional assessment in the diagnosis of malnutrition and its severity among the different studied groups, an increased prevalence of malnutrition was diagnosed by TST and the MAMC methods (with an equal frequency of $67.5 \%$ ) in the liver cirrhosis group than by the sub-scapular skin fold thickness $(52.5 \%)$, or the SGA $(37.5 \%)$ (Figures $4,5,6)$. 
Table 6. Comparison of the nutritional status among the groups based on the different anthropometric measures and SGA.

\begin{tabular}{|c|c|c|c|c|c|c|c|}
\hline \multirow{2}{*}{ Parameter } & \multicolumn{2}{|c|}{ Liver cirrhosis } & \multicolumn{2}{|c|}{ Chronic HCV } & \multicolumn{2}{|c|}{ Control } & \multirow{2}{*}{ p value } \\
\hline & $\mathrm{N}=\mathbf{4 0}$ & $\%$ & $\mathrm{~N}=\mathbf{4 0}$ & $\%$ & $\mathrm{~N}=\mathbf{4 0}$ & $\%$ & \\
\hline \multicolumn{8}{|l|}{ TST } \\
\hline Severe & 21 & $52.5 \%$ & 11 & $27.5 \%$ & 10 & $25 \%$ & \multirow{3}{*}{0.027} \\
\hline Mild-moderate & 6 & $15 \%$ & 7 & $17.5 \%$ & 0 & $0 \%$ & \\
\hline Well & 13 & $32.5 \%$ & 22 & $55 \%$ & 30 & $75 \%$ & \\
\hline \multicolumn{8}{|l|}{ МАМС } \\
\hline Severe & 12 & $30 \%$ & 15 & $37.5 \%$ & 16 & $40 \%$ & \multirow{3}{*}{$(0.132) \mathrm{NS}$} \\
\hline Mild- moderate & 15 & $37.5 \%$ & 8 & $20 \%$ & 24 & $60 \%$ & \\
\hline Well & 13 & $32.5 \%$ & 17 & $42.5 \%$ & 0 & $0 \%$ & \\
\hline \multicolumn{8}{|c|}{ Sub scapular SFT } \\
\hline Severe & 6 & $15 \%$ & 3 & $7.5 \%$ & 1 & $2.5 \%$ & \multirow{3}{*}{$(0.103) \mathrm{NS}$} \\
\hline Mild- moderate & 17 & $42.5 \%$ & 13 & $32.5 \%$ & 32 & $80 \%$ & \\
\hline Well & 17 & $42.5 \%$ & 24 & $60 \%$ & 7 & $17.5 \%$ & \\
\hline \multicolumn{8}{|l|}{ SGA } \\
\hline${ }^{*}$ Well & 25 & $62.5 \%$ & 29 & $72.5 \%$ & 37 & $92.5 \%$ & \multirow{2}{*}{$(0.958) \mathrm{NS}$} \\
\hline${ }^{* *}$ Moderate & 15 & $37.5 \%$ & 11 & $27.5 \%$ & 3 & $7.5 \%$ & \\
\hline
\end{tabular}

SGA: Subjective Global Assessment. *Well nourished on SGA rating (Grade A). **Mild to Moderately malnourished on SGA rating (Grade B). Regarding the other anthropometric measures: Well nourished: if the percentile of TSFT, MAMC and sub-scapular SFT is above the $10^{\text {th }}$ percentile, Mild to moderately malnourished: if the percentile is between the $5^{\text {th }}$ and the $10^{\text {th }}$ percentile, Severely malnourished: if the percentile is less than the $5^{\text {th }}$ percentile. These percentiles were adapted from Anthropometric Reference Data for Children and Adults: United States, 1988 - 1994, based on data from the Third National Health and Nutrition Examination Survey (NHANES III, 1988-94). P value is considered significant when $<0.05$, highly significant when $p$ value $<0.001$.

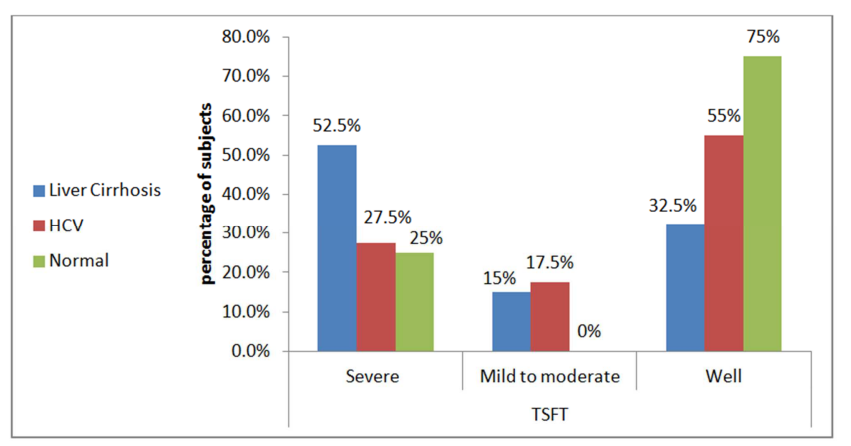

Fig. 4. Comparison of the nutritional status among the groups based on \%TST.

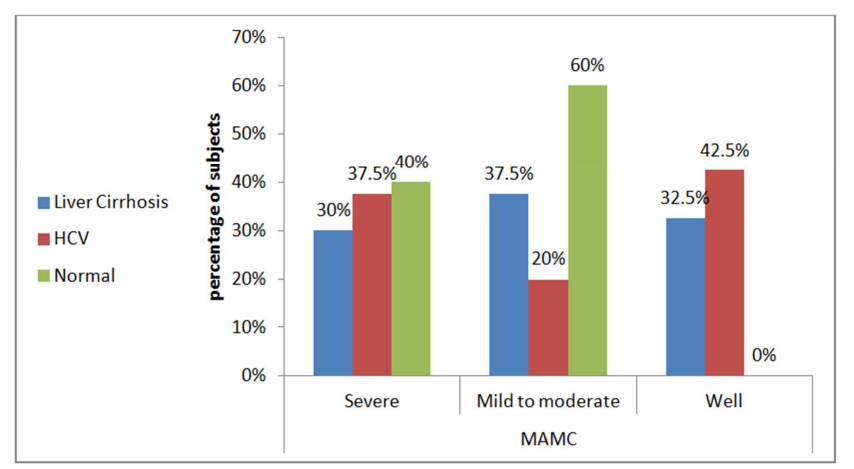

Fig. 5. Comparison of the nutritional status among the groups based on $\% M A M C$.

Moreover, the diagnosis of severe malnourishment was detected with an increased frequency in the cirrhotic patients by the TST method (52.5\%) as compared to the MAMC (30\%) and the sub-scapular skin fold thickness (15\%) (Figures 4, 5, 6). In the chronic HCV patients, an increased frequency of diagnosis of malnutrition was detected by the MAMC\% (57.5\%) as compared to the other anthropometric indices. The TST, however, underestimated the prevalence of malnutrition in the healthy control group as compared to the MAMC\% and the sub-scapular skin fold thickness.

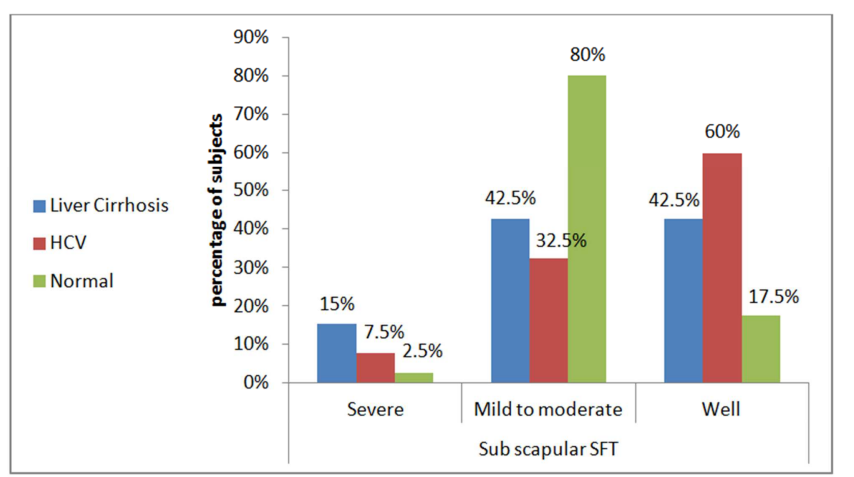

Fig. 6. Comparison of the nutritional status among the groups based on sub-scapular skin fold thickness.

Regarding Body mass index, an equal proportion $(5 \%$ (2/40)) of patients of both HCV related cirrhosis group and chronic hepatitis $\mathrm{C}$ group were found to be underweight while $2.5 \%(1 / 40)$ of the control group were found to be underweight. The frequency of the patients with compensated cirrhosis, chronic hepatitis $\mathrm{C}$ and healthy control subjects who had normal weight were $27.5 \%(11 / 40)$, $32.5 \%(13 / 40)$ and $35 \%(14 / 40)$ respectively. The majority of the patients with compensated HCV related cirrhosis and chronic HCV group as well as the healthy controls were found to be overweight $67.5 \%(27 / 40), 62.5 \%(25 / 40)$ and $62.5 \%$ (25/40) respectively) (Fig. 7). 


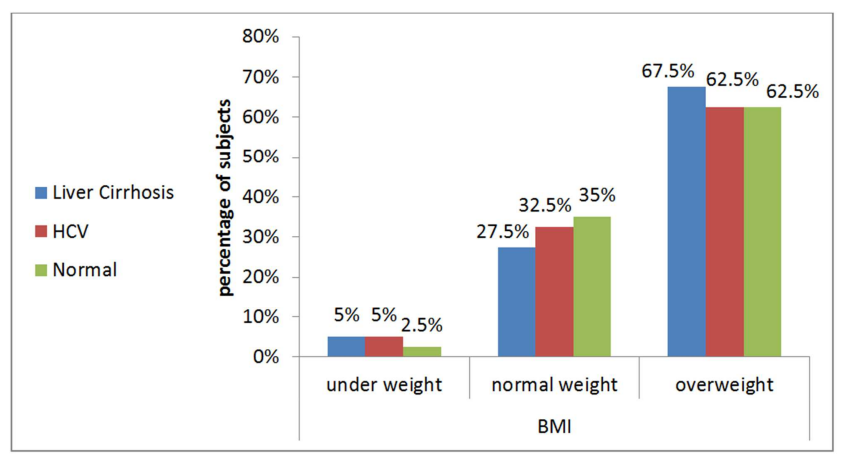

Fig. 7. Comparison of BMI among different studied groups.

When comparing the SGA with the different anthropometric measures used for assessment of nutritional status (Table 6), we found that the SGA underestimated the degree and prevalence of malnutrition in the liver cirrhosis, chronic HCV and the control groups. In chronic hepatitis C patients, we found that $37.5 \%$ of the patients who were detected to be severely malnourished on \%MAMC were found to be either well nourished $(25 \%)$ or mild to moderately malnourished (12.5\%) on SGA rating(Fig.8) but this was not statistically significant. The majority of the chronic HCV patients who were found to be well nourished on TST, MAC, MAMC and sub-scapular SFT were also found to be well nourished on SGA rating. The MAC and the sub-scapular SFT diagnosed severely malnourished chronic $\mathrm{HCV}$ patients with a very low frequency of $2.5 \%$ and $7.5 \%$ respectively (Fig. 8). The diagnosis of severely malnourished was, however, not detected by the SGA in any of the studied groups. Figure 9 shows comparison between SGA rating and the nutritional status based on the different anthropometric measures in the compensated cirrhosis group but there were no statistically significant differences.

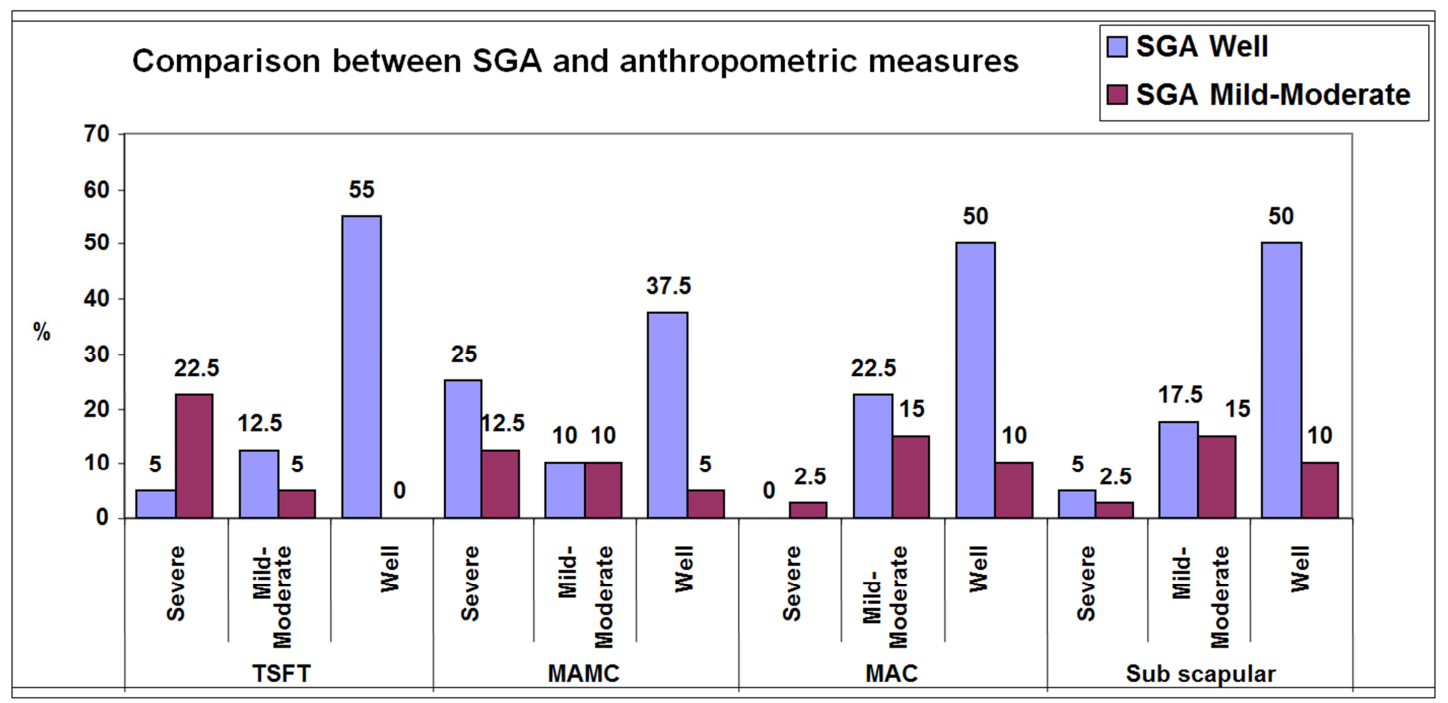

Fig. 8. Comparison between SGA rating and nutritional status assessment based on the different anthropometric measures in the chronic hepatitis C group.

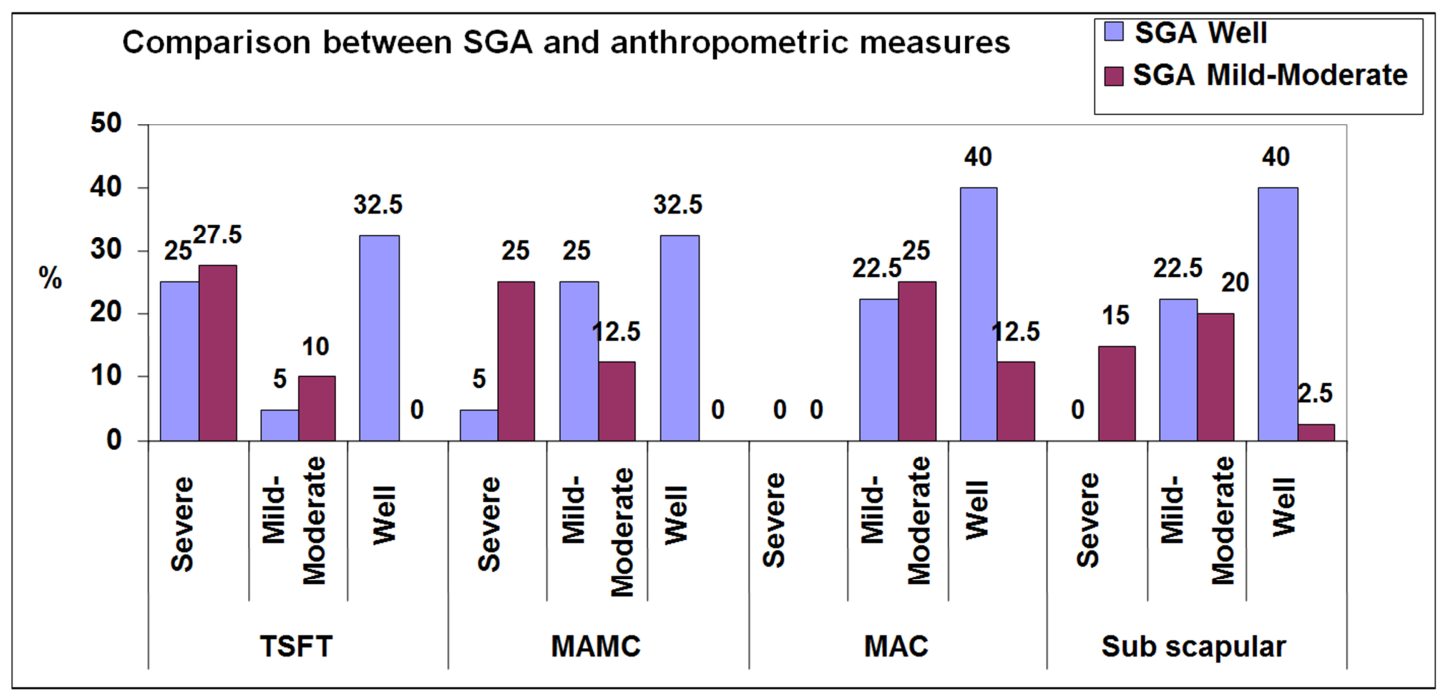

Fig. 9. Comparison between SGA rating and the nutritional status based on the different anthropometric measures in compensated cirrhosis group.There were no gender differences in the three studied groups as regard the SGA rating. However, when considering the anthropometric measures, significant gender differences were only observed in the HCV-related cirrhosis group and healthy controls as regard the TST ( $p$ values 0.024, 0.010 respectively), and the MAMC ( $p$ values 0.026, 0.000 respectively). A greater frequency of diagnosis of severely malnourished was demonstrated by the \%TST in female patients with HCV-related cirrhosis than among the male patients, however, a greater frequency of severely malnourished was recognized by the MAMC\% among the male patients. 
In chronic hepatitis $\mathrm{C}$ patients, significant gender differences were observed in the MAC $(p=0.001)$ and the MAMC $\%(p=0.050)$ with also a greater frequency of severely malnourished being observed in the male patients by the MAMC\%. No age differences were observed as regard the different anthropometric measures in the compensated cirrhosis or the chronic hepatitis $\mathrm{C}$ groups, however a significant gender difference was observed as regard the TST in the control group $(\mathrm{p}=0.002)$ with a greater frequency of moderate to severely malnourished being recognized among control subjects within the 20-40 years age group.

No significant age differences were observed in the $\mathrm{HCV}$-related cirrhosis and chronic HCV groups as regard the different anthropometric measures, however, we found a statistically significant age difference in the TST\% among the healthy control subjects $(\mathrm{p}=0.002)$ with a predominance of a low TST\%(below the $5^{\text {th }}$ percentile) in the $40-60$ years age group.

Correlation of age and BMI with the different methods of assessment of nutritional status among the three studied groups (as shown in Table 7) revealed a highly significant positive correlation between the BMI and the TST, MAC, MAMC and sub-scapular skin fold thickness in the liver cirrhosis, chronic $\mathrm{HCV}$ and healthy control groups. A non-significant inverse correlation was observed between the BMI and the SGA in the three studied groups. An inverse non-significant correlation between the age and the different anthropometric measures was observed among the studied groups.

Table 7. Correlation of BMI with anthropometric measures and SGA in HCV -related cirrhosis, chronic hepatitis $C$ \& control groups.

\begin{tabular}{llllll}
\hline \multirow{2}{*}{ Variables } & BMI/LC & & BMI/CHC & \multicolumn{2}{l}{ BMI/ Control } \\
\cline { 2 - 6 } & R & $\mathbf{p}$ & $\mathbf{R}$ & $\mathbf{P}$ & $\mathbf{R}$ \\
\hline TST & 0.622 & 0.000 & 0.672 & 0.000 & 0.831 \\
MAMC & 0.605 & 0.000 & 0.551 & 0.0351 & 0.000 \\
MAC & 0.798 & 0.000 & 0.5 & 0.04 & 0.172 \\
Sub- scapular SFT & 0.700 & 0.000 & 0.752 & 0.000 & 0.748 \\
SGA & -0.123 & 0.457 & -0.138 & 0.395 & 0.741 \\
\hline
\end{tabular}

BMI: Body mass index, LC: Liver cirrhosis, CHC: chronic hepatitis C. P value is considered significant when $<0.05$, highly significant when $\mathrm{p}$ value $<0.001$

\section{Discussion}

Liver disease affects food digestion, and the absorption, storage, metabolism and utilization of nutrients, and this may lead to vitamin and mineral deficiencies and protein energy malnutrition (PEM) [33]. Chronic hepatitis $\mathrm{C}$ virus infection is one of the chief causes of chronic liver disease with a global prevalence of about 2-3\% [34]. Malnutrition is a frequent finding in patients with chronic liver disease and can influence short and long term prognosis of those patients. Several studies have reported the prevalence of malnutrition and inadequate caloric and protein intake in cirrhotic patients candidate for liver transplantation using various methods of nutritional assessment $[13-15,17,35]$, however, only a few studies assessed patients with non-cirrhotic chronic hepatitis C $[16,18]$.

Malnutrition is considered an independent predictor of survival and Alberino et al. have demonstrated that addition of the arm muscle circumference and the triceps skin fold improves the prognostic accuracy of the Child Pugh (CP) classification. Therefore, they had suggested that nutritional status assessment could be used in conjunction with the Child Pugh (CP) classification in the evaluation of the prognosis of cirrhotic patients [36].

Several studies on the nutritional status assessment in varying aetiologies and degrees of liver insufficiency $[1,2]$ have shown that malnutrition occurs in all forms of cirrhosis [37] and its prevalence was reported to range from $65-100 \%$ depending on the severity of liver disease and the methods employed for nutritional assessment [38, 39].

In the present study the mean caloric intake in patients with
HCV-related cirrhosis was found to be $1923.75 \pm 595.8 \mathrm{kCal}$ /day and the mean protein intake was found to be $76.53 \pm 23.6$ gm/day. A study by Singh et al. reported much lower mean daily caloric $(1348.7 \pm 355.5 \mathrm{kcal} /$ day $)$ and protein intake (34.8 $\pm 8.2 \mathrm{gm} /$ day) in patients with cirrhosis that did not satisfy the nutritional requirements of those patients [40] but it was conducted on patients in different stages of alcoholic and virus related chronic liver disease.

Moreover, a study by Butt et al. conducted on patients with liver cirrhosis mostly HBV and/or HCV-related and chronic hepatitis $\mathrm{C}$, reported a much lower daily energy intake of 821 $\mathrm{Kcal} /$ day in patients with liver cirrhosis but patients with chronic hepatitis were reported to have a much better daily food intake of $1980 \mathrm{Kcal} /$ day [41]. This did not, however, agree with the findings in our study, since the chronic HCV patients were found to have lower mean daily caloric intake (1858.70 $\pm 630.2 \mathrm{Kcal} /$ day) as compared to patients with liver cirrhosis $(1923.75 \pm 595.8 \mathrm{Kcal} /$ day $)$. A possible explanation for this difference could be that the liver cirrhosis patients in the present study were all in the compensated stage (Child A) but the latter study included liver cirrhosis patients with varying severity of disease (only $34 \%$ were Child class A and the rest were Class $\mathrm{B}$ and $\mathrm{C}$ ).

Patients with HCV- related cirrhosis in the present study showed a higher prevalence of an average or an excessive intake of calories and protein rather than an insufficient intake of calories and/or protein. In fact, none of the cirrhotic patients were found to be protein- insufficient and only $15 \%$ were found to have an insufficient caloric intake. This was concordant to the results of a study by Yasutake et al. conducted on patients with HCV-related cirrhosis in the 
compensated stage $(n=47)$, chronic hepatitis $C(n=46)$ and 32 healthy volunteers, which also demonstrated that an excessive energy and /or protein intake was more prevalent in HCV-related cirrhotic patients than was an insufficient intake of calories and/or protein [11]. However, our study showed that $32.5 \%$ of the liver cirrhosis group had an excessive caloric intake as compared to $72.5 \%$ in the study by Yasutake et al. but this difference could be explained by the fact that the latter study included cirrhotic patients with diabetes which were found to have even significantly higher intake levels of energy and proteins than cirrhotic patients without diabetes [11]. These patterns of nutritive intake as shown in our study therefore suggest that protein energy malnutrition (PEM) may not be observed as a frequent finding in liver cirrhosis particularly in the compensated stage.

Caloric (energy) overconsumption was not observed in patients with chronic hepatitis $\mathrm{C}$ in our study. Moreover, a much lower frequency of excessive protein intake was observed in chronic $\mathrm{HCV}$ patients as compared to that of patients with liver cirrhosis $(37.5 \%$ vs $67.5 \%$ respectively). This was also in agreement with Yasutake et al. who also reported higher intake levels of calories, protein and fat in patients with $\mathrm{HCV}$ - related cirrhosis as compared to chronic HCV patients and healthy volunteers [11].

When categorizing cirrhotic patients according to daily caloric and protein intake, we found a significant association $(p=0.011)$ between the caloric and protein intake. Most of the cirrhotic patients who had caloric overconsumption had an average protein intake while most of the patients with an average caloric intake showed overconsumption of proteins. There was also a significant association between caloric and protein intake in the chronic HCV group $(p=0.016)$; with the majority of the patients with an insufficient caloric intake showing overconsumption of proteins. Our findings may thus indicate inappropriate dietary habits in patients with compensated liver cirrhosis which could be attributable to lack of effective nutritional education.

An important finding in the present study was that there was only a significant difference between the studied groups as regard nutritional status assessment by \%TST with a $p$ value $=0.027$. The compensated cirrhosis group showed that $67.5 \%$ of the patients were malnourished when using $\% \mathrm{TST}$. $45 \%$ of the patients in the chronic hepatitis $\mathrm{C}$ group, and $25 \%$ of the healthy volunteers were found to be malnourished using the \%TST as a method of nutritional assessment. This is in accordance with a study by Vieira et al. which also reported that \%TST was the anthropometric method that most frequently diagnosed malnutrition among patients with cirrhosis of varying aetiology, with a greater frequency of severely malnourished being demonstrated among those patients classified as Child Pugh $\mathrm{C}$ than among those classified as A [8].

Although, it was expected that the frequency of diagnosis of malnutrition using the \%TST method in patients with liver cirrhosis would be reduced as compared to the other anthropometric methods because the presence of swelling could possibly conceal a depletion in adipose tissue, yet it has been reported that the upper limbs are not the preferential place of oedema in patients with chronic liver disease [8].

In the present study a greater frequency of malnutrition was diagnosed in chronic hepatitis $\mathrm{C}$ patients $(57.5 \%)$ and healthy control subjects $(100 \%)$ by the \% MAMC analysis as compared to the \%TST method. There was a comparable frequency of diagnosis of malnutrition in patients with compensated cirrhosis by the \%MAMC and the \%TST methods although severe malnutrition was diagnosed in a greater number of cirrhotic patients using the latter method. The differences in the nutritional status between the studied groups using the \%MAMC analysis did not, however, reach statistical significance.

In a study by Carvalho and Parise conducted on nonhospitalized patients with liver cirrhosis, a high prevalence of malnutrition was observed in patients in the early stages of the disease [14]. Some of the particularly important causes of malnutrition in these patients are inadequate food intake, malabsorption and metabolic disorders. Insufficient food intake could be attributed to physical symptoms of discomfort, loss of appetite related to increased regulation of inflammation and of appetite mediators, or lack of interest in food resulting from food restrictions or changes in taste [9].

When considering the BMI as a method of assessment of nutritional status, we did not find any significant differences between the three studied groups $(\mathrm{p}=0.916)$, but an important observation was a higher than expected prevalence of overweight among the chronic HCV (62.5\%) and the compensated liver cirrhosis groups $(67.5 \%)$. This was in accordance with a Brazilian study by Gottschall et al. assessing the nutritional status in non-cirrhotic chronic hepatitis $\mathrm{C}$ patients which also reported an increase in the prevalence of overweight among the studied population [42] and explained that this could be a consequence of unfavourable changes in the dietary patterns such as an increased consumption of processed food or a decrease in the occupational energy expenditure [43].

Regarding gender differences in anthropometric measures in the different studied groups, we observed significant gender differences in the \% TST and \%MAMC in patients with HCV related cirrhosis and in healthy control subjects. In chronic hepatitis $\mathrm{C}$ patients, significant gender differences were observed in the MAC and the MAMC\%. A greater frequency of diagnosis of severely malnourished was demonstrated by the \%TST in female patients with HCV-related cirrhosis than among male patients, however, a greater frequency of severely malnourished was recognized by the MAMC\% among the male patients. This is in agreement with studies which also demonstrated that the adipose tissue is more depleted among the women and that the muscular mass is more depleted among the men $[8,14]$. Norman et al. have explained the greater decrease of muscular mass among men with liver cirrhosis to be linked to the onset of feminization provoked by decreased serum testosterone levels as a result of its decreased production and its increased transformation into estrogen in the liver [44].

An important finding in the present study was that the BMI 
correlated significantly with the anthropometric indices (TST, MAC, MAMC and sub-scapular skin fold thickness) but showed a non-significant inverse correlation with SGA in the liver cirrhosis, chronic hepatitis $\mathrm{C}$ and control groups. This is in accordance with the study by Butt et al. which also revealed a statistically significant correlation $(\mathrm{p}=0.000)$ between BMI and MAMC values and average daily food intake in patients with chronic HCV and liver cirrhosis [41].

There were highly significant statistical differences between the different studied groups as regard the different components of SGA namely weight loss $(\mathrm{p}=0.008)$, dietary intake $(p=0.0013)$, functional capacity $(p=0.008)$ and GIT symptoms ( $p$ value $=0.008$ ), however, regarding the SGA rating, we did not observe any significant differences between the studied groups $(p=0.958)$. The majority of patients with HCV- related cirrhosis $(62.5 \%)$ and chronic hepatitis $\mathrm{C}$ (72.5\%) scored an ' $\mathrm{A}$ ' (well nourished) on SGA rating, the rest were mildly- moderately malnourished (Grade B) $(37.5 \%$ and $27.5 \%$ respectively) and none of patients of either groups were severely malnourished.

This was in agreement with a study by Ismail et al. conducted to assess the nutritional status in patients with hepatitis $\mathrm{C}$ at all stages of the disease using the SGA as a screening tool, which showed that the majority of the patients with chronic HCV (86\%) were also well nourished and 14\% were moderately malnourished (scored a 'B') on the SGA rating [18]. They have also reported that the majority of healthy control subjects $(97 \%)$ were well nourished (scored an ' $A$ ' on SGA) and this was comparable to the findings of our study as most of the healthy controls (92.5\%) were Grade A (best nutritional status) and only $7.5 \%$ were mild-moderately malnourished. They had expected, however, to find the nutritional status of patients with chronic hepatitis $\mathrm{C}$ to be closely matched to the healthy control subjects but this was not the case and they suggested that this was most probably a result of restricted protein and caloric intake. Similarly a study by Gottschall et al. found a significant risk of malnutrition in the chronic hepatitis $\mathrm{C}$ group which was found to be $16 \%$ [42].

However, in contrast to our findings the minority of the patients with compensated cirrhosis in the study by Ismail et al. were found to be well nourished $(10 \%)$ with the majority $(56 \%)$ being moderately malnourished (Grade B) and 34\% being severely malnourished on the SGA and they attributed this to protein caloric malnutrition which promotes catabolism and hypoalbuminemia. Patients with compensated cirrhosis already have substantial hepatic injury and thus malnutrition hastens their progression to the decompensated stage, as there is a direct relation between the severity of malnutrition and the progression of liver disease [45, 46].

The use of the SGA was recommended by the 2006 guidelines of the European Society of Enteral and Parenteral Nutrition (ESPEN) [47], together with anthropometric analysis and handgrip strength test (HGS) for identifying patients with cirrhosis who are at risk of malnutrition [9]. The SGA is a commonly used tool for the assessment of nutritional status in various diseases including cirrhosis and chronic hepatitis $\mathrm{C}$ with an inter-observer reproducibility rate of $80 \%$ [31]. It has been validated in candidates of liver transplantation [48] and has not proved to be less superior to more complex scoring systems in identifying malnutrition [49].

The sensitivity of the SGA in patients with cirrhosis has been questioned in several studies. Figueiredo et al. compared three methods of nutritional assessment for patients with liver cirrhosis: SGA, conventional nutritional parameters (anthropometric measures), and multiple compartment body composition analysis (DEXA scan). They identified the prevalence of PEM in the cohort of patients with cirrhosis as $32 \%$ by SGA and $30 \%$ by conventional parameters, and reported that these two methods may underestimate the prevalence of PEM, in comparison with a multi compartment body composition analysis. In fact, the latter method indicated a higher prevalence of $60 \%$ for patients with Child's class A or B cirrhosis and a higher prevalence of $20 \%$ for those with Child's class C disease [50].

When comparing the SGA with the different anthropometric methods in the present study, we found that the SGA underestimated the degree and prevalence of malnutrition as compared to TST, MAMC and sub-scapular skin fold thickness in the liver cirrhosis, chronic hepatitis $\mathrm{C}$ and healthy control groups. This was in agreement with previous studies which have also reported that the SGA was found to underestimate the nutritional state in the majority of patients with liver cirrhosis with a low sensitivity for nutritional diagnosis [51]. This could be explained by the fact that the SGA incorporates multiple factors and clinical criteria that influence and determine the nutritional status rather than using objective measurements [52].

Assessing the nutritional status and dietary intake patterns in patients with chronic hepatitis $\mathrm{C}$ and compensated liver cirrhosis may, therefore, substantiate nutrition education strategies as preventive measures in the development of malnutrition in patients with chronic liver disease [42].

Some of the limitations of our study were a relatively small sample size and there were certain limitations for the use of SGA as it somewhat depended on the patient's own history especially when asking about the percentage of weight loss which might have been under or over estimated by the patients. It is also worth noting that the 24 dietary recall method which was used in this study to assess patients' dietary intake, had been applied only once, thus, the dietary intake assessment may have occurred on an atypical day, that did not reflect the patient's usual daily intake.

\section{Conclusion}

Overweight was prevalent among patients with chronic $\mathrm{HCV}$ and compensated cirrhosis. SGA underestimated the degree and prevalence of malnutrition as compared to TSFT, MAMC and sub-scapular skin fold thickness in the liver cirrhosis, chronic hepatitis $\mathrm{C}$ and healthy control groups. Therefore, regular assessment of nutritive intake and nutritional status is mandatory, better using anthropometric measurements such as the BMI, TST and MAMC as simple and early predictors of malnutrition, in order to identify 
patients at risk and their nutritional problems for adequate guidance regarding the nutritive management and to establish effective nutritional education systems

\section{References}

[1] Italian Multicentre Cooperative Project on Nutrition in Liver Cirrhosis. Nutritional status in cirrhosis. J Hepatol. 1994; 21: 317-25.

[2] Muller MJ. Malnutrition in cirrhosis. J Hepatol. 1995; 23: 31-35.

[3] Lautz HU, Selberg O, Korber J, Bürger M, Müller MJ. Protein- calorie malnutrition in liver cirrhosis. Clin Investig. 1992; 70: 478-86.

[4] Guglielmi FW, Panella C, Buda A et al. "Nutritional state and energy balance in cirrhotic patients with or without hypermetabolism. Multicentre prospective study by the "Nutritional Problems in Gastroenterology" Section of the Italian Society of Gastroenterology (SIGE)," Digestive and Liver Disease, 2005; 37(9): 681-688.

[5] DiCecco SR, Wieners EJ, Wiesner RH, Southorn PA, Plevak DJ, Krom RA. Assessment of nutritional status of patients with end stage liver disease undergoing liver transplantation. Mayo Clin Proc 1989; 64: 95-102.

[6] Shepard CW, Finelli L, Alter MJ. Global epidemiology of hepatitis C virus infection. Lancet Infect Dis. 2005; 5: 558-67.

[7] Roongpisuthipong C, Sobhonslidsuk A, Nantiruj K, Songchitsomboon S. Nutritional assessment in various stages of liver cirrhosis. Nutrition 2001; 17: 761-5.

[8] Vieira PM, De-Souza DA and Oliveira LCM. Nutritional assessment in hepatic cirrhosis; clinical, anthropometric, biochemical and haematological parameters. Nutr Hosp. 2013; 28(5): 1615-1621.

[9] Cheung K, Lee SS and Raman M. Prevalence and mechanisms of malnutrition in patients with advanced liver disease, and nutrition management strategies. Clin Gastroenterol Hepatol 2012; 10: 117-25.

[10] Balbino V, Castro e Silva O. Nutritional assessment of cirrhotic patients: A new approach based on electrical bioimpedance. Medicina (Ribeirăo Preto) 2012; 45(1): 1-4.

[11] Yasutake K, Bekki M, Ichinose M, Ikemoto M, Fujino T, Ryu T, Wada Y, Takami Y, Saitsu H. Assessing current nutritional status of patients with HCV-related liver cirrhosis in the compensated stage. Asia Pac J Clin Nutr 2012; 21 (3): 400-405.

[12] Alveras-da-Silva MR, Reverbel da Silveira T. Comparison between handgrip strength, subjective global assessment, and prognostic nutritional index in assessing malnutrition and predicting clinical outcome in cirrhotic outpatients. Nutrition 2005; 21: 113-7.

[13] Bragança ACC and Álvares-da-Silva MR. Prevalence of diabetes mellitus and impaired glucose tolerance in patients with decompensated cirrhosis being evaluated for liver transplantation: the utility of oral glucose tolerance test. Arq Gastroenterol. 2010; 47(1): 22-7.

[14] Carvalho L and Parise ER. Evaluation of nutritional status of nonhospitalized patients with liver cirrhosis. Arq Gastroenterol. 2006; 43(4): 269-74.

[15] Ferreira LG, Anastácio LR, Lima AS, Correia MITD. Desnutrição e inadequação alimentar de pacientes aguardando transplante hepático. Rev Assoc Med Brás. 2009; 55(4): 389-93.

[16] Gottschall CBA, Nunes FF, Aydos MED, Bragança AC, Felix DR, Rabito EI, Álvares-da-Silva MR. Contribution of dynamometry and the royal free hospital global assessment to the nutritional assessment of patients with chronic liver diseases. Rev Chil Nutr. 2012; 39(4): 152-8.

[17] Peng S, Plank LD, McCall, JL, Gillanders LK, McIlroy K, Gane E. Body com $\neg$ position, musclefunction, and energy expenditure in patients with liver cirrhosis: a comprehensive study. Am J Clin Nutr. 2007; 85: 1257-66.

[18] Ismail FW, Khan ' RA, Kamani L, Wadalawala AA, Shah HA, Hamid SS, Jafri W. Nutritional status in patients with hepatitis C. J Coll Physicians Surg Pak. 2012; 22(3): 139-42.

[19] Muto Y, Sato S, Watanabe A, Moriwaki H, Suzuki K, Kato A, et al. Overweight and obesity increase the risk for liver cancer in patients with liver cirrhosis and long-term oral supplementation with branched-chain amino acid granules inhibits liver carcinogenesis in heavier patients with liver cirrhosis. Hepatol Res. 2006; 35: 204-14.

[20] Poon RT, Yu WC, Fan ST, Wong J. Long-term oral branched chain amino acids in patients undergoing chemoembolization for hepatocellular carcinoma: a randomized trial. Aliment Pharmacol Ther. 2004; 19: 779-88.

[21] Nakaya Y, Okita K, Suzuki K, Moriwaki H, Kato A, Miwa Y, et al. BCAA-enriched snack improves nutritional state of cirrhosis. Nutrition. 2007; 23: 113-20.

[22] Aoyama K, Tsuchiya M, Mori K, Kubo Y, Shiraishi K, Sakaguchi E, Yamashita S, Sakaida I. Effect of a late evening snack on outpatients with liver cirrhosis. Hepatol Res. 2007; 37: 608-14.

[23] World Medical Association. "Declaration of Helsinki: Ethical Principles for Medical Research Involving Human Subjects". JAMA 2013; 310 (20): 2191-2194.

[24] Anthropometric Reference Data for Children and Adults: United States, 1988 - 1994, based on data from the Third National Health and Nutrition Examination Survey (NHANES III, 1988-94).

[25] Blackburn GL, Harvey KB. Nutritional assessment as a routine in clinical medicine. Postgrad Med 1982; 71: 46-63.

[26] National Nutrition Institute (2006) Food Composition Tables for Egypt. 2nd Edition, ARE, Cairo, 119.

[27] Food and Nutrition Board, Institute of Medicine: Dietary Reference Intakes for Energy, Carbohydrate, Fiber, Fat, Fatty Acids, Cholesterol, Protein, and Amino Acids (Macronutrients) Washington, DC: National Academy Press, 2005.

[28] Detsky AS, McLaughlin JR, Baker JP, Johnston N, Whittaker S, Mendelson RA et al. What is subjective global assessment of nutritional status? JPEN J Parenter Enteral Nutr 1987; 11: 8- 13.

[29] Baker JP, Detsky AS, Wesson DE et al. "Nutritional assessment: a comparison of clinical judgement and objective measurements," New England Journal of Medicine, 1982; 306(16): 969-972. 
[30] Tai ML, Goh KL, Mohd-Taib SH, Rampal S, Mahadeva S. Anthropometric, biochemical and clinical assessment of malnutrition in Malaysian patients with advanced cirrhosis. Nutr J 2010; 9: 1-7.

[31] Hasse J, Strong S, Gorman MA, Liepa G. Subjective global assessment: alternative nutrition-assessment technique for liver-transplant candidates. Nutrition 1993; 9: 339-43.

[32] Covinsky KE et al. "The relationship between clinical assessments of nutritional status and adverse outcomes in older hospitalized medical patients", Journal of American Geriatric Society. 1999; 47: 532-8.

[33] Canadian guidelines for Health Care Providers. Hepatitis C: Nutrition Care. Dietitians of Canada, 2003.

[34] World Health Organization, Geneva. Weekly Epidemiological Record. 1997; 46: 341-8.

[35] Gottschall, CBA, Álvares-da-Silva MR, Camargo ACR, Burtett RM, Silveira TR. Nutritional assessment in patients with cirrhosis: the use of indirect calorimetry. Arq Gastroenterol. 2004; 41(4): 220-4.

[36] Alberino F, Gatta A, Amodio P, Merkel C, Di Pascoli L, Boffo $\mathrm{G}$, et al. Nutrition and survival in patients with liver cirrhosis. Nutrition 2001; 17: 445-50.

[37] Caregaro L, Alberino F, Amodio P, Merkel C, Bolognesi M, Angeli $\mathrm{P}$, et al. Malnutrition in alcoholic and virus-related cirrhosis. Am J Clin Nutr 1996; 63: 602-9.

[38] Campillo B, Richardet J-P, Scherman E, et al. Evaluation of nutritional practice in hospitalized cirrhotic patients: results of a prospective study. Nutrition 2003; 19: 515-521.

[39] O'Brien A and Williams R. Nutrition in end-stage liver disease: principles and practice. Gastroenterology 2008; 134: 1729-1740.

[40] Singh N, Choudhary JK, Srivastava M, Tripathi MK, Rungta S, Singh SK, Jain AK, Dixit VK. Nutritional And Clinical Profile Of Patients In Different Stages Of Alcoholic And Virus Related Liver Disease: An Indian Perspective. Webmed Central plus GASTROENTEROLOGY 2013: WMCPLS00239.

[41] Butt S, Ahmed P, Liaqat P and Ahmad H. A study of malnutrition among chronic liver disease patients. Pakistan Journal of Nutrition 2009; 8(9): 1465-1471.
[42] Gottschall CBA, Pereira TG, Rabito EI, Álvares-da-Silva MR. Nutritional status and dietary intake in non-cirrhotic adult chronic hepatitis C patients. Arq Gastroenterol 2015; 52(3): 204-9.

[43] Schmidt MI, Duncan BB, Silva GA, Menezes AN, Monteiro CA, Barreto SM, Chor D, Menezes PR. Chronic non-communicable diseases in Brazil: burden and current challenges. Lancet. 2011; 9; 61-74.

[44] Norman K, Valentini L, Lochs H, Pirlich M. Protein Catabolism and Malnutrition in Liver Cirrhosis - Impact of Oral Nutritional Therapy. Z Gastroenterol 2010; 48 (7): 763-70.

[45] Merli M, Riggio O, Dally L. Does malnutrition affect survival in cirrhosis? PINC (Policentrica Italiana Nutrizione Cirrosi). Hepatology, 1996; 23: 1041-1046.

[46] Henkel AS and Buchman AL. Nutritional support in patients with chronic liver disease. Nat Clin Pract Gastroenterol Hepatol 2006; 3: 202-9.

[47] Plauth M, Cabre E, Riggio O et al. ESPEN Guidelines on Enteral Nutrition: Liver disease. Clinical Nutrition, 2006; 25: 285-294.

[48] Stephenson GR, Moretti EW, El-Moalem H, et al. Malnutrition in liver transplant patients: preoperative subjective global assessment is predictive of outcome after liver transplantation. Transplantation 2001; 27: 666-670.

[49] Plauth M, Merli M, Kondrup J, Weimann A, Ferenci P, Müller MJ. ESPEN Consensus Group. Guidelines for nutrition in liver disease and transplantation. Clin Nutr 1997; 16: 43-55.

[50] Figueiredo FAF, Perez RM, Freitas MM, and Kondo M. "Comparison of threemethods of nutritional assessment in liver cirrhosis: subjective global assessment, traditional nutritional parameters, and body composition analysis," Journal of Gastroenterology 2006; 41(5): 476-482.

[51] Fernandes SA, Bassani L, Nunes FF, Aydos MED, Alves AV, Marroni CA. Nutritional Assessment in patients with cirrhosis. Arq Gastroenterol 2012; 49: 19-27.

[52] Gunsar F, Raimondo ML, Jones S, et al. Nutritional status and prognosis in cirrhotic patients. Aliment Pharmacol Ther. 2006; 24: 563-572. 